\title{
Analisis Konsentrasi Cairan Infus Terhadap Tegangan Pada Sensor Infus
}

\author{
Rizka Silviana Hartanti ${ }^{1)}$, Sulhadi ${ }^{2}$, Mahardika Prasetya Aji ${ }^{3)}$ \\ ${ }^{1,2,3)}$ Program Pasca Sarjana Pendidikan Fisika UNNES Kampus Unnes Bendan Ngisor, Semarang 50233, Jawa Tengah \\ 1) SMK NU Hasyim Asy'ari 1, Kudus, Jawa Tengah \\ E-mail: rizkasilviana.h@gmail.com
}

\begin{abstract}
Abstrak. Rumah sakit adalah tempat dimana orang sakit akan berobat ataupun bahkan menginap untuk kesembuhan penyakitnya. Pasien yang di rawat di rumah sakit banyak yang membutuhkan infus untuk menstabilkan dirinya dari sakit yang dideritanya .Infus digunakan sebagai cairan atau obat untuk penyembuhan pada pasien. Cairan infus yang habis maka harus segera diganti dengan yang baru. Untuk memudahkan pihak keluarga dan perawat dengan mengirim informasi bahwa infus habis maka di butuhkan sensor infus.Cairan infus memiliki berbagai macam jenis dengan konsentrasi yang berbeda. Untuk itu diperlukan adanya penelitian mengenai analisis konsentrasi cairan infus terhadap tegangan yang keluar pada sensor infus.Metode penelitian yang dilakukan yaitu menggunakan rangkaian sensor infus. Sensor infus yang digunakan adalah sensor infus yang terdiri dari sensor cahaya dengan detector cahaya photodioda dan receiver cahaya yaitu infrared yang dipasang di leher botol kaca infus sebagai variabel control yang berisi cairan infus $\mathrm{NaCl}$ dengan berbagai konsentrasi sebagai variabel bebas kemudian diukur tegangan yang keluar sebagai variabel terikat. Hasil penelitian yang dilakukan adalah ketika kondisi sensor tanpa hambatan menghasilkan tegangan rata-rata 4,19V.Kondisi sensor melalui botol kaca kosong menghasilkan tegangan rata-rata 4,35V. Kondisi sensor melalui botol kaca berisi cairan infus $\mathrm{NaCl}$ dengan konsentrasi masing-masing 1,67\%; 3,34\%; 6,69\% menghasilkan tegangan rata-rata masing-masing yaitu 4,40V; 4,43V; 4,45V. Dapat disimpulkan bahwa semakin besar konsentrasi cairan didalam botol kaca maka semakin besar cahaya yang diserap dan semakin kecil cahaya yang diteruskan. Ketika hambatan yang dilalui semakin besar maka cahaya dari infrared yang sampai ke photodioda semakin kecil sehingga tegangan yang dihasilkan semakin besar. Sehingga pada penelitian ini ketika tegangan dalam rentang 4,40-4,45V maka alarm pada sensor infus tidak berbunyi.
\end{abstract}

Kata Kunci: sensor infus, konsentrasi, cairan infus, tegangan

\section{PENDAHULUAN}

Rumah sakit adalah tempat dimana orang sakit akan berobat ataupun bahkan menginap untuk kesembuhan penyakitnya. Orang yang sedang sakit dan menginap di rumah sakit disebut pasien rumah sakit. Pasien yang di rawat di rumah sakit banyak yang membutuhkan infus untuk menstabilkan dirinya dari sakit yang dideritanya. Selain itu kebanyakan sekarang banyak pengobatan pada pasien yang diberikan melalui infus untuk memudahkan obat masuk kedalam tubuh pasien sehingga bekerja secara optimal. Sehingga dapat disimpulkan bahwa infus merupakan bagian terpenting dari pengobatan untuk pasien yang dirawat di rumah sakit.

Infus merupakan salah satu fasilitas untuk pasien yang diberikan oleh rumah sakit. Alat infus ini digunakan untuk memberikan cairan ataupun obat kepada pasien. Pada beberapa rumah sakit, alat infus masih dipasang secara manual.Sehingga masih membutuhkan ekstra perhatian dari perawat rumah sakit untuk sering meninjau pasien tiap kamar.

Pasien yang rawat inap di rumah sakit biasanya membutuhkan keluarga untuk menemaninya sekaligus mengawasi infus yang ada pada pasien, karena jika cairan infus sampai kehabisan maka darah pada pasien akan tertarik ke selang infus. Ketika infus habis maka pasien dan keluarga harus segera memberitahu perawat yang jaga dengan menekan tombol agar perawat segera mengganti dengan cairan infus yang baru. Jadi agar tidak terjadi keterlambatan dalam mengganti cairan infus maka keluarga pasien harus selalu terjaga. 
Masalah tersebut akan membuat ketidaknyamanan dari pasien dan juga keluarga pasien. Untuk itu dibutuhkan sebuah alat yang otomatis agar pasien dan keluarga merasa nyaman dan juga perawat tidak selalu mengecek ke ruangan setiap pasien. Maka dari itu, untuk mengatasi masalah tersebut dibangun sebuah sensor infus untuk mengetahui habis atau tidaknya cairan di dalam infus tersebut yang akan dihubungkan langsung ke ruang perawat jaga agar memudahkan perawat untuk mengetahui infus yang habis pada pasien dan segera menggantinya dengan yang baru.

Cairan infus memiliki beberapa macam-macam cairan, diantaranya yaitu $\mathrm{NaCl}, \mathrm{C} 6 \mathrm{H} 12 \mathrm{O} 6, \mathrm{KCl}$, dan lain-lain.Cairan infus dibagi dalam 3 jenis yaitu cairan hipotonik, isotonic dan hipertonik.Pada setiap jenis tersebut mengandung $\mathrm{NaCl}$.Maka $\mathrm{NaCl}$ merupakan cairan yang sering digunakan dalam infus pasien.Setiap cairan infus juga memiliki konsentrasi yang berbeda sesuai yang dibutuhkan oleh pasien.Maka dari itu dibutuhkan analisis mengenai konsentrasi cairan terhadap tegangan pada sensor infus.

Salah satu sensor infus terbuat dari sensor cahaya.Sensor cahaya merupakan cahaya yang di konversikan ke tegangan melalui detector cahaya dan receiver infrared. Detector cahaya yang digunakan yaitu photodioda.Photodioda merupakan jenis dioda yang berfungsi mendeteksi cahaya. Komponen elektronika ini akan mengubah cahaya menjadi arus listrik. Cahaya yang dapat dideteksi oleh photodioda ini mulai dari cahaya infra merah, cahaya tampak, ultra ungu sampai dengan sinar-X. Photodioda dibuat dari semikonduktor dengan bahan yang populer adalah silicon $(\mathrm{Si})$ atau galium arsenida (GaAs), dan yang lain meliputi InSb, InAs, PbSe. Material ini menyerap cahaya dengan karakteristik panjang gelombang mencakup: 2500-11000 ̊ untuk silicon, 8000-20,000Å untuk GaAs. Ketika sebuah photon (satu satuan energi dalam cahaya) dari sumber cahaya diserap, hal tersebut membangkitkan suatu elektron dan menghasilkan sepasang pembawa muatan tunggal, sebuah elektron dan sebuah hole, di mana suatu hole adalah bagian dari kisi-kisi semikonduktor yang kehilangan elektron. Arah Arus yang melalui sebuah semikonduktor adalah

kebalikan dengan gerak muatan pembawa.Cara tersebut di dalam sebuah photodioda digunakan untuk mengumpulkan photon - menyebabkan pembawa muatan (seperti arus atau tegangan) mengalir/terbentuk di bagian-bagian elektroda. Sehingga jika foton semakin banyak dikumpulkan maka arus semakin rendah maka tegangan juga rendah karena arah arus yang melalui sebuah semikonduktor adalah kebalikan dari gerak muatan pembawa.

Receiver infrared yaitu komponen yang merubah energi cahaya, dalam hal ini energi cahaya infra merah, menjadi pulsa-pulsa sinyal listrik.Komponen ini harus mampu mengumpulkan sinyal infra merah sebanyak mungkin sehingga pulsa-pulsa sinyal listrik yang dihasilkan kualitasnya cukup baik. Semakin besar intensitas infra merah yang diterima maka sinyal pulsa listrik yang dihasilkan akan baik jika sinyal infra merah yang diterima intensitasnya lemah maka infra merah tersebut harus mempunyai pengumpul cahaya (light collector) yang cukup baik.

Cahaya adalah suatu pancaran gelombang elektromagnetik yang dapat ditangkap oleh mata.Perambatan gelombang cahaya tidak memerlukan medium.Kecepatan gelombang cahaya besarnya $3 \times 10^{8} \mathrm{~m} / \mathrm{s}$. Ketika cahaya mengenai sebuah penghalang cairan maka cahaya ada yang diserap dan ada yang diteruskan.

Apabila seberkas cahaya melalui suatu cairan maka sebagian cahaya tersebut sebagian akan diserap oleh cairan berbanding langsung dengan konsentrasi cairan dan tebal sel wadah. Seberkas cahaya yang apabila melewati suatu cairan yang konsentrasinya c maka sinar tersebut sebagian akan diserap dan sebagian akan diteruskan. Jumlah sinar yang diserap oleh cairan berbanding lansung dengan konsentrasi cairan dan tebal sel /wadah. Hubungan ini dirumuskan oleh Lambert-Beer.

Hukum Beer : Absorbans, log $(\mathrm{Po} / \mathrm{P})$, radiasi monokromatik berbanding lurus dengan konsentrasi satu spesies penyerap dalam larutan.

Hukum Bouguer (Lambert) : Bayangkan suatu medium penyerap yang homogen dalam lapisan-lapisan yang sama tebal. Tiap lapisan menyerap radiasi monokromatik yang memasuki lapisan itu dalam fraksi yang sama seperti lapisan- 


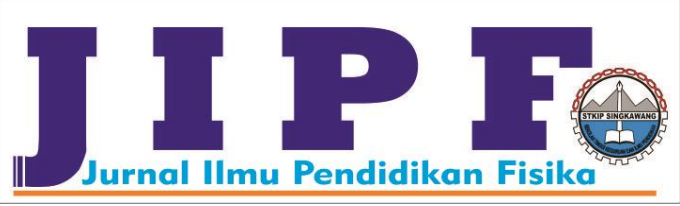

lapisan lain. Dengan semuanya yang lain sama, maka absorbans itu berbanding lurus dengan panjang jalan yang melewati medium.

Cairan yang memiliki konsentrasi yang berbeda maka kekeruhannya juga berbeda, sehingga mempengaruhi jalannya cahaya.Nilai kekeruhan air berbanding terbalik dengan nilai intensitas cahaya, dimana semakin besar nilai kekeruhan air maka semakin kecil nilai intensitas cahaya.

\section{Metode}

Penelitian ini dilakukan untuk menganalisis konsentrasi cairan infus terhadap tegangan pada sensor infus. Variabel kontrol dalam eksperimen ini yaitu ketebalan botol infus, botol yang digunakan yaitu botol yang terbuat dari kaca dengan ketebalan yang sama. Variabel terikat dalam eksperimen ini yaitu tegangan yang keluar dari sensor infus ketika melewati cairan dan botol.Variabel bebas dalam eksperimen ini yaitu konsentrasi cairan.Cairan yang digunakan yaitu cairan infus yang sering digunakan untuk pasien yaitu $\mathrm{NaCl}$ dengan konsentrasi larutan yang berbeda-beda.

Alat dan bahan yang digunakan dalam eksperimen ini yaitu botol kaca infus, cairan $\mathrm{NaCl}$, rangkaian sensor cahaya yang menggunakan photodioda dan receiver infrared.

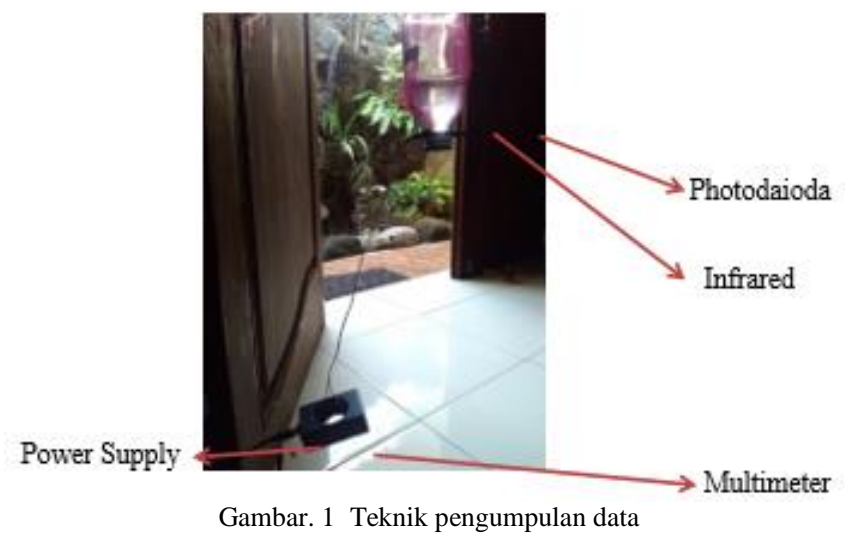

Langkah awal yang dilakukan adalah membuat rangkaian sensor cahaya.Salah satu sensor infus yaitu menggunakan sensor cahaya untuk mendeteksi cairan.Penelitian ini dilakukan dengan menggunakan sensor cahaya karena mudah didapatkan dan harga terjangkau.Sensor cahaya di dalam penelitian ini yaitu menggunakan
Jurnal Ilmu Pendidikan Fisika

Volum 1 Nomor 2 September 2016. Halaman 45-48 p-ISSN: 2477-5959 e-ISSN: 2477-8451

photodioda, receiver infrared, resistor, cermet dan IC LM350.Sensor cahaya tersebut dipasang pada leher botol yang berisi cairan dengan konsentrasi berbeda kemudian diukur tegangan yang keluar.

Pengambilan data dalam penelitian ini yaitu dengan mencatat hasil pengukuran yang didapatkan yaitu tegangan yang dihasilkan dari berbagai konsentrasi cairan $\mathrm{NaCl}$ menggunakan multimeter. Teknik analisis data dalam penelitian ini menggunakan grafik satu dimensi yaitu grafik konsentrasi cairan terhadap tegangan yang dihasilkan pada sensor cahaya.

\section{HASIL DAN PEMBAHASAN}

Berdasarkan eksperimen yang dilakukan sehingga didapatkan tegangan keluar yang dihasilkan setelah sensor cahaya melewati botol dan cairan dengan konsentrasi yang berbeda. Hasil tegangan yang keluar terdapat di tabel 1

TABEL 1

HASIL TEGANGAN YANG KELUAR DARI PENGAMBILAN DATA

\begin{tabular}{clc}
\hline No & Kondisi sensor cahaya & Tegangan rata-rata (V) \\
\hline 1. & Tanpa hambatan & 4,19 \\
2. & Botol tanpa cairan & 4,35 \\
3. & Botol berisi cairan 1,67\% & 4,40 \\
4. & Botol berisi cairan 3,34\% & 4,43 \\
5. & Botol berisi cairan 6,69\% & 4,45 \\
\hline
\end{tabular}

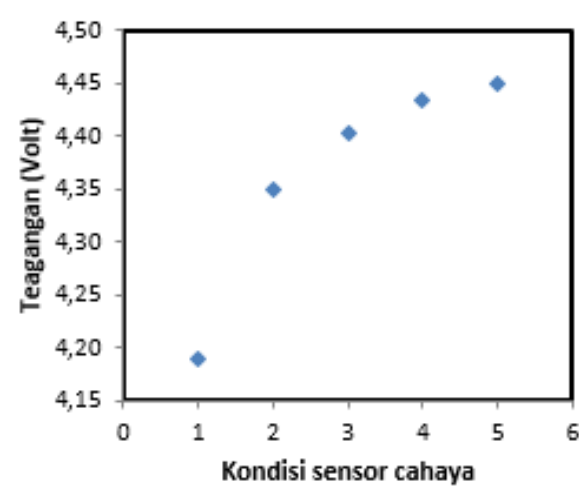

Gambar. 2 Grafik kondisi sensor terhadap tegangan

Dari gambar 2 didapatkan bahwa pada saat kondisi 1 ketika sensor cahaya tanpa hambatan menghasilkan tegangan rata-rata 4,19V. Infrared yang mengenai photodioda tanpa hambatan maka cahaya diteruskan seluruhnya sehingga tegangan rata-rata yang dihasilkan yaitu $4,19 \mathrm{~V}$.

Pada saat kondisi 2 ketika sensor cahaya melalui botol kaca tanpa cairan menghasilkan tegangan rata-rata 4,35V.Pada kondisi 2, infrared yang mengenai photodioda melalui botol kaca tanpa 


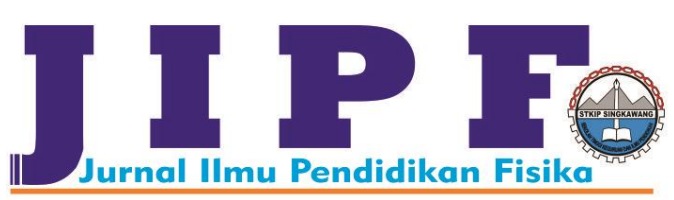

cairan maka cahaya ada yang diserap dan diteruskan. Ketika cahaya diserap oleh botol kaca maka cahaya yang diteruskan akan berkurang sehingga cahaya yang diteruskan sampai ke photodioda menghasilkan tegangan rata-rata $4,35 \mathrm{~V}$.

Pada saat kondisi 3-5, infrared yang mengenai photodioda melalui botol kaca berisi cairan dengan konsentrasi masing-masing yaitu 1,67\%; $3,34 \% ; 6,69 \%$ menghasilkan tegangan rata-rata masing-masing yaitu 4,40V; 4,43V; 4,45V. Pada kondisi 3-5, infrared yang mengenai photodioda melalui botol kaca yang berisi cairan maka cahaya ada yang terserap dan ada yang diteruskan. Ketika cahaya yang diserap oleh botol kaca dan cairan maka cahaya yang diteruskan akan semakin berkurang karena cahaya yang diserap semakin banyak, sehingga cahaya yang diteruskan sampai ke photodioda akan semakin berkurang dan tegangan rata-rata masing-masing yang dihasilkan 4,40V; 4,43V; 4,45V.

Dari hasil penelitian yang didapatkan, hal ini berkaitan dengan daya serap cahaya yang melalui suatu cairan dan sel wadahnya yang dikemukakan oleh Lambert dan Beer yaitu Seberkas cahaya yang apabila melewati suatu larutan yang konsentrasinya c maka sinar tersebut sebagian akan diserap dan sebagian akan diteruskan. Jumlah cahaya yang diserap oleh larutan berbanding lurus dengan konsentrasi larutan dan tebal sel /wadah. Maka dari hasil penelitian dapat dilihat bahwa semakin besar konsentrasi cairan di dalam botol kaca maka semakin besar cahaya yang diserap dan semakin kecil cahaya yang diteruskan sehingga tegangan yang dihasilkan semakin besar.

\section{KESIMPULAN}

Dari penelitian yang dilakukan dapat disimpulkan bahwa tegangan yang dihasilkan paling kecil yaitu pada saat kondisi sensor tanpa hambatan sehingga tegangan rata-rata yang dihasilkan 4,19V. Sedangkan tegangan yang dihasilkan paling besar yaitu pada saat kondisi sensor melalui botol kaca berisi cairan dengan konsentrasi $6,69 \%$ sehingga tegangan rata-rata yang dihasilkan 4,45V. Dapat disimpulkan bahwa semakin besar konsentrasi cairan didalam botol kaca maka semakin besar cahaya yang diserap dan

semakin kecil cahaya yang diteruskan.Ketika hambatan yang dilalui semakin besar maka cahaya dari infrared yang sampai ke photodiode semakin kecil sehingga tegangan yang dihasilkan semakin besar. Sehingga dapat dilihat bahwa pada tegangan dalam rentang 4,40-4,45V maka alarm pada sensor infus tidak berbunyi.

Adapun saran dalam penelitian ini adalah perlu dilakukan penelitian mengenai rancang bangun sensor infus otomatis yang berbentuk alarm tanpa kabel karena penelitian sebelumnya sensor infus meggunakan kabel sehingga kurang praktis untuk digunakan.

\section{UCAPAN TERIMAKASIH}

Terima kasih kepada pihak-pihak yang telah membantu dalam penulisan ini, antara lain dosen pembimbing yang telah membimbing sampai penulisan selesai, Bang Adi Irawan yang turut membantu dalam penelitian hingga selesai. Dan teman-teman yang tak dapat disebutkan satu persatu.

\section{DAFTAR PUSTAKA}

[1] Ana. (2015). Jenis-jenis Cairan Infus dan Fungsinya. [Online] Tersedia : http://halosehat.com/review/tindakan-medis/jenis-jeniscairan-infus. Diakses tanggal 5 Mei 2016

[2] Anam, Moch Choirul, "Modul Elektronika”, Pasuruan, 2008

[3] Anggraini, Dika Febi. (2016). Pengembangan Sistem Monitoring Tetesan Infus Pada Ruang Perawatan Rumah Sakit. [Online]. Tersedia : http://www.Distrodoc.com/287211. Diakses tanggal 30 Mei 2016

[4] Gunarta, Lilik, "Photodioda dan Infrared", 2011.

[5] Muljodipo, Nuryanto, "Rancang Bangun Otomatis Sistem Infus Pasien". Manado : UNSRAT, 2015

[6] Nasrudin, Akhmad Akhsin, "Rancang Bangun Aplikasi Lux Meter Bh1750 Sebagai Alat Ukur Kekeruhan Air Berbasis Mikrokontroler", Surabaya : UNESA, 2015

[7] Sora. (2015). Pengertian Cahaya Dan Sifatnya Serta Contohnya. [Online]. Tersedia : $\quad$ http://www.pengertianku.net /2015/06/pengertian-cahaya-dan-sifatnya-serta-contohnya.html. diakses tanggal 5 Mei 2016

[8] Syahrul, "Sistem Pemantauan Infus Pasien Terpusat", Bandung UKI, 2009.

[9] Timbang Rasa. 2011. Infus cairan intravena (Macam-macam cairan Infus).[Online]. Tersedia http://timbangrasaclinic.blogspot.co.id/2011/10/infus-cairanintravena-macam-macam.html. Diakses tanggal 1 Juni 2016

[10] Wayan, Suryagama I, "Laporan Resmi Instrumen Analisa penentuan Panjang Gelombang”, Yogyakarta : Akademi Teknologi, 2009. 